\title{
Implicações do plano de desenvolvimento da educação para a formação de professores
}

Gisele Masson*

\section{Resumo}

0 artigo analisa as principais implicações do Plano de Desenvolvimento da Educação (PDE) para a formação de professores. A pesquisa utilizou fontes bibliográficas e documentais e foi fundamentada na concepção materialista histórica e dialética. A proposta para a formação de professores presente no PDE é neopragmatista, pois reforça a importância da busca de instrumentos úteis para as demandas imediatas da prática profissional e não contribui para o desenvolvimento de uma sólida e ampla formação. A prioridade dada à formação de professores como solução para os resultados negativos obtidos pelo Índice de Desenvolvimento da Educação Básica (Ideb), em vez de um investimento financeiro adequado, revela a prioridade dada às condições subjetivas na resolução dos problemas educacionais.

Palavras-chave: Política educacional. Plano de Desenvolvimento da Educação. Fundamentos teóricos. Formação de professores.

\section{Implications of the development plan of education for teacher training Abstract}

This paper analyzes the main implications of the Development Plan of Education (DPE) for teacher training. The research used bibliographic and documentary sources and was based on historical and dialectical materialism concepts. The teacher training education proposal presented by the DPE is neo pragmatist, since it reinforces the importance of searching for instruments that are useful to the immediate demands of the teaching profession and it doesn't contribute to developing a solid and broad education. The fact that it gives priority to teacher training education rather than to proper financial investments as the solution for the negative results registered by the Basic Education Development

\footnotetext{
* Doutora em Educação, Universidade Estadual de Ponta Grossa (UEPG). E-mail: gimasson@uol.com.br
} 
Index (Ideb) brings out the given priority to the subjective conditions in the resolution of educational problems.

Keywords: Education policy. Education Development Plan. Theoretical foundations. Teacher education/training.

\section{Implicaciones del plan de desarrollo de la educación para la formación de profesores Resumen}

Este trabajo analiza las principales implicaciones del Plan de Desarrollo de la Educación (PDE), Brasil, para la formación continuada de profesores. La investigación utilizó fuentes bibliográficas y documentales y se basó en la concepción materialista histórica y dialéctica. La propuesta para la formación de profesores presente en el PDE es neopragmatista, pues corrobora la importancia de la búsqueda de instrumentos provechosos para las demandas inmediatas de la práctica profesional y no contribuye para el desarrollo de una sólida y amplia formación. La prioridad dada a la formación de profesores como solución de los resultados negativos del Índice de Desarrollo de la Educación Básica (Ideb) en vez de un inversión financiera adecuada pone de manifiesto la prioridad dada a las condiciones subjetivas en la solución de los problemas educacionales.

Palabras clave: Politica educacional. Plan de Desarrollo de la Educación. Fundamentos teóricos. Formación de profesores.

\section{Introdução}

0 presente artigo aborda o debate originado a partir da aprovação do Plano de Desenvolvimento da Educação (PDE), os fundamentos teóricos apresentados no documento divulgado pelo Ministério da Educação, bem como a proposta de formação de professores dele decorrente.

0 principal objetivo é analisar o PDE a fim de explicitar a concepção de educação adotada e sua repercussão no campo da formação de professores. Ele representa um plano de governo para a educação bastante ambicioso, o qual pretende diminuir a fragmentação das políticas educacionais e englobar diversas ações para a melhoria da qualidade do ensino no Brasil. Sua aprovação gerou amplas discussões entre os pesquisadores da educação, especialmente pela forma como ele foi planejado e aprovado. Apesar das críticas, alguns autores como Saviani (2007), Mendonça (2007) e Gracindo (2007) destacam que o PDE tem um sentido positivo ao demonstrar uma preocupação com o problema qualitativo da educação brasileira e com as políticas de financiamento que buscam erradicar o analfabetismo. Em que pese tal positividade, sua proposta para a formação de professores não contribui para concretização da concepção sócio-histórica defendida pelo movimento de educadores. 


\title{
O Plano de Desenvolvimento da Educação (PDE): sua fundamentação, seus avanços e limites
}

0 PDE foi apresentado em 15 de março de 2007 e lançado oficialmente pelo MEC no dia 24 de abril, agregando ações que pretendem contribuir para melhorar a qualidade da educação. Saviani (2007, p.1233) afirma que

\begin{abstract}
[...] na verdade, o denominado PDE aparece como um grande guarda-chuva que abriga praticamente todos os programas em desenvolvimento pelo MEC. Ao que parece, na circunstância do lançamento do Programa de Aceleração do Crescimento (PAC) pelo governo federal, cada ministério teria que indicar as ações que se enquadrariam no referido Programa. 0 MEC aproveitou, então, o ensejo e lançou o Índice de Desenvolvimento da Educação Básica (IDEB) e a ele atrelou as diversas ações que já se encontravam na pauta do Ministério, ajustando e atualizando algumas delas.
\end{abstract}

Partindo da análise de Saviani (2007), o PDE não pode ser desvinculado das estratégias mais amplas que buscam acelerar o crescimento econômico do país. Há uma profunda articulação entre o PAC e o PDE, pois, na ótica do Estado, os avanços econômicos dependem de ações no campo da educação que possibilitem a preparação dos sujeitos para as demandas do contexto produtivo, demonstrando que o PDE é um plano de governo para a educação.

O PDE gerou uma série de manifestações, tanto favoráveis quanto desfavoráveis. Lideranças e pesquisadores da educação posicionaram-se de forma contrária à maneira como o PDE foi planejado. Ruiz (2007), Helena de Freitas (2007b), Aguiar (2007), Mendonça (2007), Gracindo (2007) e Cara (2007) destacaram a ausência de um amplo diálogo entre as instituições e profissionais que militam na educação, no processo de elaboração do referido plano. Ao eleger alguns interlocutores, o MEC afastou outros da discussão e planejamento das propostas do PDE. Helena de Freitas (2007b, p. 14) considera que

[...] ao eleger os segmentos envolvidos no movimento Todos pela Educação [...] como os interlocutores válidos, indica que serão estes segmentos da sociedade civil organizados nas ONGs, empresariado, Conselho Nacional de Secretários de Educação (Consed) e Undime, que passarão a orientar as ações e dirigir programas nas escolas da educação básica.

Além dessa questão, outros problemas são apontados como: a) a predominância de uma concepção de educação que prioriza resultados, pois o plano está ancorado em um índice de desenvolvimento da educação de natureza puramente quantitativa 
(RUIZ, 2007; MENDONÇA, 2007); b) a descontinuidade das politicas, especialmente porque o PDE não foi elaborado a partir do Plano Nacional de Educação (PNE), de 2001 (FREITAS, H., 2007b); c) a tendência de se considerar que o fracasso da educação é apenas um problema gerencial (GRACINDO, 2007).

Outro questionamento bastante frequente entre os pesquisadores foi sobre a possibilidade de o PDE ser chamado de "Plano". De acordo com Saviani (2007, p. 1239), ao confrontarmos o PNE 1 com o PDE, é possivel constatar que o segundo não pode ser denominado de plano. "Ele se constitui, antes, como um conjunto de ações que, teoricamente, se constituiriam em estratégias para a realização dos objetivos e metas previstos no PNE." Apenas no plano teórico, as ações do PDE buscam concretizar os objetivos do PNE, mas de fato ele não parte do diagnóstico, das diretrizes e das metas deste último (SAVIANI, 2007).

Ruiz (2007, p. 9) considera que "o nome de Plano não coaduna com o seu conteúdo. Teria sido melhor, de acordo com o apresentado, chamá-lo de Ações para o Desenvolvimento da Educação, pois é isso que ele lembra." Gracindo (2007, p. 29) também considera que "[...] o PDE não é um Plano, na concepção tradicional de documento que reflete um planejamento organicamente construído, com propostas de objetivos e metas a serem alcançados." 0 PDE, para Cara (2007, p. 35),

[...] não possui a envergadura de um plano. Conceitualmente, um plano se compõe por um conjunto de medidas estruturadas e articuladas entre si, visando a um objetivo. A eleição, a estruturação e a articulação dessas ações são justificadas pela elaboração de um diagnóstico crítico, seguida pelo estabelecimento de um cronograma de implantação e execução das mesmas. Esta última etapa deve ser monitorada e avaliada por meio do cumprimento de metas, quantitativas e/ou qualitativas.

A despeito de tais considerações, é necessário levar em conta que o PDE representa a sistematização de necessidades e demandas que advêm das lutas entre grupos sociais distintos e que almejam concretizar determinado projeto de sociedade. Aguiar (2007) destaca que as políticas públicas resultam das lutas entre grupos sociais e, conforme o resultado dos embates, há aqueles que conseguem inscrever suas demandas na agenda de governo. Assim, a autora enfatiza a importância da mobilização docente na definição de políticas educacionais:

1 Vale destacar, a partir dos estudos de Saviani (2007), que o PNE foi aprovado no segundo mandato de Fernando Henrique Cardoso e sofreu nove vetos do presidente que inviabilizaram a implantação de uma série de importantes reivindicações. 0 Partido dos Trabalhadores encabeçou a apresentação do PNE a partir das propostas dos Congressos Nacionais de Educação, entretanto, a vitória de Lula nas eleições de 2002 não fez com que os vetos do presidente anterior fossem derrubados. 
Não obstante os avanços conseguidos em decorrência das lutas empreendidas, os educadores, historicamente, não têm conseguido alcançar todos os objetivos inscritos em suas pautas de reivindicações há mais de duas décadas. $E$ dificilmente essas reivindicações serão atendidas plenamente. Isto significa, numa determinada perspectiva, que precisamos estar permanentemente engajados nas lutas, nos espaços que sejam atinentes à nossa própria atuação como profissionais e como cidadãos. (AGUIAR, 2007, p. 18).

A autora também destaca a necessidade de compreendermos as intensas disputas que geram decisões no interior do aparelho de Estado. Enfatiza que os setores organizados da sociedade civil eram entendidos como forças sociais progressistas, de esquerda. Todavia, uma análise mais atenta do cenário atual do nosso país revela que vários grupos estão organizados no sentido de influenciar os rumos da política nacional. Na Educação, o movimento Compromisso Todos pela Educação é "[...] um movimento capitaneado por empresários que emergiu recentemente na sociedade, e que certamente dispõe de recursos de poder para influenciar o campo da política de educação básica. É um novo ator que aparece e oriundo da sociedade civil" (AGUIAR, 2007, p. 19).

Sobre essa questão, Martins (2009, p. 27) destaca que tal movimento

[...] atua segundo as referências do neoliberalismo da Terceira Via, uma proposta neoliberal para o século XXI, preconizando a possibilidade da existência de um "capitalismo de face humanizada", justamente quando as formas de exploração se radicalizam chegando a níveis dramáticos para a existência humana.

Apesar dos problemas apontados, o PDE tem um sentido positivo, conforme análise de Saviani (2007), pois demonstra uma preocupação em atacar o problema qualitativo da Educação Básica brasileira. Sob a perspectiva de Mendonça (2007), uma dimensão positiva do PDE é o fato de a educação ser incluída na agenda do país como aspecto necessário e relevante para o seu desenvolvimento. Gracindo (2007) também destaca que muitas ações do PDE são positivas em relação às políticas de financiamento que buscam erradicar o analfabetismo. Não aprofundarei a análise de todas as ações que compõem o PDE no sentido de apontar os seus problemas e avanços para a educação brasileira. Destacarei, contudo, as bases conceituais do PDE e as questões que se relacionam diretamente com as politicas de formação de professores.

O PDE está sustentado em seis pilares conceituais: visão sistêmica da educação, territorialidade, desenvolvimento, regime de colaboração, responsabilização e mobilização social (BRASIL, [2007]). 
No livro intitulado 0 plano de desenvolvimento da educação: razões, princípios e programas que, embora sem data, foi lançado em outubro de $2007^{2}$, estabelece-se uma aproximação da noção de sistema com o enfoque sistêmico. Entretanto, o PDE não explicita a concepção que fundamenta a visão sistêmica adotada. Mas, de acordo com Saviani (2008, p. 229), "[...] não podemos perder de vista que a organização dos sistemas nacionais de ensino antecede historicamente em mais de um século ao advento do chamado 'enfoque sistêmico'. Portanto, trata-se de coisas distintas." Saviani (2008, p. 229-230) explica que o enfoque sistêmico é um conceito epistemológico que se articula ao método estrutural-funcionalista de analisar os fenômenos e, quando aplicado à educação, esse enfoque diz respeito a um dos possíveis modos de se analisar o fenômeno educativo. "Em contrapartida, a noção de sistema educacional tem caráter ontológico, pois se refere ao modo como o próprio fenômeno educativo é (ou deve ser) organizado" (SAVIANI, 2008, p. 229-230).

A visão sistêmica da educação se desenvolve no PDE a partir do pressuposto de que o desenvolvimento nacional só será garantido "[...] se a educação for alçada à condição de eixo estruturante da ação do Estado de forma a potencializar seus efeitos" (BRASIL, [2007], p. 6). Para tanto, é necessário, de acordo com o PDE, a construção da unidade dos sistemas educacionais como sistema nacional, garantindo a multiplicidade e não a uniformidade. A concepção adotada é explicitada nos seguintes termos:

Diferentemente da visão sistêmica que pauta o PDE, predominou no Brasil, até muito recentemente, uma visão fragmentada da educação, como se níveis, etapas e modalidades não fossem momentos de um processo, cada qual com objetivo particular, integrados numa unidade geral; como se não fossem elos de uma cadeia que deveriam se reforçar mutuamente. Tal visão fragmentada partiu de princípios gerencialistas e fiscalistas, que tomaram os investimentos em educação como gastos, em um suposto contexto de restrição fiscal. (BRASIL, [2007], p. 7).

0 que se observa é que o enfoque sistêmico embasa o PDE, que tem como um dos objetivos integrar a Educação Brasileira, todavia, não há uma única forma de abordar a concepção sistêmica. Essa concepção foi proposta, inicialmente, por Kahn e Katz, tomando como base a teoria geral dos sistemas do biólogo Von Bertalanffy (1975) que procurou introduzir, no campo das ciências sociais, conceitos da física, da biologia e da cibernética, demonstrando uma tendência de integração das ciências naturais e sociais.

20 lançamento do livro com a justificação e exposição dos princípios do PDE só ocorreu quando a proposta já estava em execução. 
Ludwig Von Bertanffy (1975, p. 75-76) apresentou a Teoria Geral dos Sistemas pela primeira vez em 1937, no seminário de filosofia de Charles Morris na Universidade de Chicago, e foi resumida da seguinte maneira:

Até aqui a unificação da ciência tem sido vista como a redução de todas as ciências à física, a resolução final de todos os fenômenos em acontecimentos físicos. De nosso ponto de vista a unidade da ciência ganha um aspecto mais realista. A concepção unitária do mundo pode ser baseada não na esperança possivelmente fútil e certamente forçada de reduzir por fim todos os níveis da realidade ao nível da física, mas antes na isomorfia das leis em diferentes campos.

0 sistema foi definido por Von Bertalanffy (1975, p. 84) como um complexo de elementos em interação. $\mathrm{Na}$ análise do autor, a teoria geral dos sistemas deveria ser um dispositivo regulador na ciência, "[...] deveria ser metodologicamente um importante meio para controlar e investigar a transferência de princípios de um campo para outro, a fim de que não seja mais necessário duplicar ou triplicar a descoberta dos mesmos princípios [...]" (VON BERTALANFFY, 1975, p. 115).

A incorporação das contribuições de Von Bertalanffy (1975), nas análises de Katz e Khan (1970) foi adaptada e recebeu influências do funcionalismo de Talcott Parsons. Na obra Psicologia Social das Organizações, Katz e Kahn (1970) consideram as organizações como sistemas abertos de papéis, normas e valores que reduzem a variabilidade do comportamento humano e promovem a adaptação ao ambiente. A ênfase na funcionalidade dos sistemas destaca que os valores e normas promovem o equilibrio e a adaptação social dos sistemas organizacionais. A vertente funcionalista não aborda a historicidade dos sistemas sociais e omite os seus conflitos, pois descreve as instituições sociais apenas através de seus efeitos e não explica a causa desses efeitos.

Saviani (2009, p. 22-23) afirma que

pela sua vinculação com o método estrutural-funcionalista, o "enfoque sistêmico" resulta incompatível com a perspectiva de superação das dicotomias, identificada com a visão dialética, presente no "Livro sobre o PDE". Com efeito, o "enfoque sistêmico" deriva de uma concepção mecanicista que tende a perpetuar a forma de sociedade existente.

Apesar do enfoque sistêmico se originar do método estrutural-funcionalista, a teoria sistêmica assume novas configurações na atualidade, por isso, não é possível analisar com segurança qual concepção subsidia o PDE, pois o documento não explicita em 
detalhes qual abordagem o fundamenta. Para Vasconcellos (2009), o pensamento sistêmico é o novo paradigma da ciência que engloba o paradigma da complexidade, o paradigma da instabilidade e o paradigma da intersubjetividade. A autora explica:

Por isso, quando falo de novo paradigma da ciência, estou implicitamente falando desses vários "paradigmas pós-modernos" ou dessas várias "epistemologias pósmodernas" e propondo pensarmos sempre em sua articulação. Afinal, distinguir as conexões e articulações também é uma característica da forma sistêmica de pensar. (VASCONCELLOS, 2009, p. 154).

Conforme análise da autora, a teoria sistêmica novo-paradigmática se diferencia da Teoria Geral dos Sistemas por colocar a objetividade entre parênteses, ou seja, a subjetividade do observador sai de dentro dos parênteses em que foi colocada pela ciência tradicional. Assim, "a validação das experiências subjetivas se fará, criando-se espaços consensuais, nos quais a ciência possa se desenvolver, com o novo pressuposto, que é o da intersubjetividade. Fica claro, então, que esse jamais será um espaço da verdade, mas um espaço de consenso, de acoplamento estrutural entre observadores" (VASCONCELLOS, 2009, p. 140). Desse ponto de vista, a realidade é uma construção; por isso, é impossivel apreendê-la de forma objetiva. A dificuldade em analisar a visão sistêmica presente no PDE reside no fato de que não há um aprofundamento quanto à concepção de enfoque sistêmico adotada, podendo ocasionar interpretações equivocadas no seu processo de execução.

A educação, na perspectiva assumida no documento do PDE, busca promover relações com a ordenação do território e com o desenvolvimento econômico e social. No PDE (BRASIL, [2007], p. 6) "o enlace entre educação e ordenação territorial é essencial na medida em que é no território que as clivagens culturais e sociais, dadas pela geografia e pela história, se estabelecem e se reproduzem". A consideração de que as clivagens culturais e sociais derivam da geografia e da história é uma abstração mistificadora. 0 antagonismo estrutural entre capital e trabalho como gerador das desigualdades sociais sequer é mencionado no plano. Assim, considerase que "o enlace entre educação e desenvolvimento é essencial na medida em que é por meio dele que se visualizam e se constituem as interfaces entre a educação como um todo e as outras áreas de atuação do Estado" (BRASIL, [2007], p. 6-7).

A intenção de promover o enlace entre educação, ordenação do território e desenvolvimento econômico e social se configura, com o PAC e o PDE, como planos de ação governamental que demandam a colaboração dos entes federados para a sua concretização. Assim, o regime de colaboração, como um dos pilares do PDE, é reafirmado a partir dos principios constitucionais que organizam as competências da União, dos Estados, do Distrito Federal e dos municípios em matéria educacional. 
No PDE (BRASIL, [2007], p. 10), o "regime de colaboração significa compartilhar competências políticas, técnicas e financeiras para a execução de programas de manutenção e desenvolvimento da educação, de forma a concertar a atuação dos entes federados sem ferir-Ihes a autonomia."

A União passa a assumir, com o PDE, maiores compromissos financeiros e, em contrapartida, utiliza mecanismos de responsabilização, valorizando a mobilização social para o acompanhamento e fiscalização das ações educacionais. A justificativa para a definição desses propósitos é a seguinte:

Se a educação é definida, constitucionalmente, como direito de todos e dever do Estado e da família, exige-se considerar necessariamente a responsabilização, sobretudo da classe política, e a mobilização da sociedade como dimensões indispensáveis de um plano de desenvolvimento da educação. (BRASIL, [2007], p. 11).

Conforme análise de Luiz Carlos de Freitas (2007, p. 964), está ocorrendo um aprofundamento das políticas liberais da era FHC sob o governo de Luiz Inácio Lula da Silva. "Os que nele votamos esperávamos, já no primeiro mandato, uma mudança significativa de rota. Não ocorreu. Agora, assistimos à sua conversão plena às propostas liberais de 'responsabilização' [...]".

A responsabilização (accountability) ${ }^{3}$ deve ser substituída, segundo Luiz Carlos de Freitas (2007), por uma visão de participação e envolvimento local na vida da escola para a melhoria da qualidade, com vistas à igualdade de resultados. A mera igualdade de oportunidades é uma estratégia da ideologia liberal que se baseia na meritocracia. Essa ideologia se expressa no PDE (BRASIL [2007], p. 6) que busca "[...] garantir a todos e a cada um o direito de aprender até onde o permitam suas aptidões e vontade. [...] A razão de ser do PDE está precisamente na necessidade de enfrentar estruturalmente a desigualdade de oportunidades educacionais."

Na opinião de Mészáros (2007, p. 234, grifo do autor), "[...] a proclamada 'igualdade de oportunidade' não poderia corresponder a nada mais do que a uma concha formal vazia. Pois a fórmula em si mesma tem como premissa explícita a rejeição implacável e cínica da 'igualdade de início'".

0 viés meritocrático também aparece no documento do PDE, ao citar as diretrizes que orientam o Plano de Metas Compromisso Todos pela Educação. Dentre

3 Não é possível traduzir com exatidão o termo em inglês accountability. Ele tem sido traduzido como responsabilidade, responsabilização, no sentido de prestação de contas. Como conceito, accountability tem origem na gestão empresarial e se refere à prestação de contas centrada nos resultados. 
elas, destacam-se "valorizar o mérito do trabalhador da educação; fixar regras claras, considerados mérito e desempenho, para nomeação e exoneração de diretor de escola" (BRASIL, [2007], p. 24).

A responsabilização recai sobre os alunos e os profissionais que trabalham na escola, já que as políticas educacionais "oportunizam igualmente" o direito de aprender. Luiz Carlos de Freitas (2007, p. 981) destaca que a questão central não é ser contra a avaliação externa, mas ser "[...] contra o uso da avaliação externa tendo como pano de fundo a 'teoria da responsabilização' liberal. A responsabilização pressupõe uma linha direta de pressão sobre os municípios, o que poderá levar a toda sorte de armadilhas para se obter recursos."

Não obstante a crítica aos princípios gerencialistas no campo educacional, o PDE, ao adotar a visão sistêmica e a responsabilização como conceitos basilares, acaba recaindo numa abordagem liberal e gerencial que introduz a lógica da produtividade existente no setor privado.

O surgimento do modelo gerencial (managerialism) de Estado ocorreu, segundo Abrucio (1997), a partir de um conjunto de fatores: crise econômica mundial, iniciada em 1973, na primeira crise do petróleo, e retomada ainda com mais força em 1979, na segunda crise do petróleo. Esse momento de escassez gerou uma grave crise fiscal do Estado, a globalização e todas as transformações tecnológicas que transformaram a lógica do setor produtivo também afetaram o Estado, resultando na perda de parcela significativa do seu poder de ditar políticas macroeconômicas.

Os precursores do modelo gerencialista puro foram os conservadores ingleses e os republicanos americanos ${ }^{4}$. Foi, porém, modificado por um processo de defesa da modernização do setor público e pela incorporação de conceitos como busca contínua da qualidade, descentralização e avaliação dos serviços públicos pelos consumidores/cidadãos (ABRUCIO, 1997).

No Quadro 1, Abrucio (1997, p. 12) compara as três visões da administração pública inglesa que surgiram do debate sobre o managerialism aplicado ao governo:

Quadro 1 - Respostas à crise do modelo burocrático inglês.

\begin{tabular}{|c|c|c|}
\hline Modelo gerencial puro & Consumerism & Public service orientation \\
\hline Economia/eficiência(produtividade) & Efetividade/qualidade & Accontability/equidade \\
\hline Taxpayers (contribuintes) & Clientes/consumidores & Cidadãos \\
\hline
\end{tabular}

Fonte: 0 autor (2010).

4 Os governos neoliberais de Thatcher (1979, Grã-Bretanha) e Reagan (1980, EUA) foram os pioneiros na reformulação da administração pública baseada no modelo gerencialista puro que tinha como principais objetivos a busca da eficiência e produtividade, com a redução dos gastos públicos. 
Importa destacar que há diferenças entre as teorias, mas elas não são excludentes. 0 princípio da responsabilização (accontability) deriva do modelo gerencial puro, que apresentava limites, porque valorizava a mensuração da eficiência e não da efetividade dos serviços públicos (ABRUCIO, 1997).

A ênfase na responsabilização e na mobilização social como dimensões indispensáveis para a concretização dos objetivos do PDE revela que o modelo gerencialista associado ao enfoque sistêmico são princípios que fundamentam a administração pública da educação no governo Lula. Dourado (2007, p. 932) considera que "o PDE, nesse cenário, tem foco e ação político-pedagógica baseados em concepção gerencial, cujo processo ignora o esforço desenvolvido pelo MEC no apoio técnico e financeiro para a democratização da gestão escolar."

Na seção seguinte, darei prosseguimento à análise do PDE, com destaque às principais propostas para a formação/ treinamento de professores.

\section{O PDE e suas propostas para a formação de professores: a Universidade Aberta do Brasil como prioridade}

0 PDE apresenta como questões centrais a formação de professores e a valorização dos profissionais da educação. A Universidade Aberta do Brasil (UAB), o Programa Institucional de Bolsas de Iniciação à Docência (Pibid) e a Coordenação de Aperfeiçoamento de Pessoal de Nivel Superior (Capes), que passa a fomentar a formação de pessoal de nível superior para todos os níveis da educação, são as principais ações do PDE para a formação de professores.

A prioridade dada pelo PDE à Universidade Aberta do Brasil (UAB) para a formação de professores tem suscitado discussões entre os pesquisadores da área. $A$ formação continuada de professores, bem como a formação inicial de professores em exercício já vinha acontecendo, desde o início do governo Lula, por meio de programas de formação a distância. Entretanto, a criação da $U A B^{5}$, oferecendo prioritariamente cursos de licenciatura, demonstrou uma expansão da formação inicial de professores na modalidade a distância.

De um lado, tal ação contribuirá para limitar, senão inviabilizar, a disseminação de cursos de formação a distância aligeirados e mercantilizados, pois a ênfase dada à oferta de cursos superiores a distância em universidade públicas de forma articulada com os polos de apoio presencial poderá conferir-Ihes maior grau de qualidade. Por outro lado,

5 A Universidade Aberta do Brasil foi criada em 2005 e aprovada pelo Decreto no 5.800 (BRASIL, 2006), voltada para o desenvolvimento da modalidade de educação a distância, com a finalidade de expandir e interiorizar a oferta de cursos e programas de Educação Superior no país. 
contraria a posição do movimento de educadores, que considera que programas de educação a distância para a formação de professores deviam ser antecedidos pela formação inicial presencial. 0 ensino a distância, para Saviani (2007, p. 1250),

[...] como a base dos cursos de formação docente não deixa de ser problemático, pois arrisca converter-se num mecanismo de certificação antes que de qualificação efetiva. Esta exige cursos regulares, de longa duração, ministrados em instituições sólidas e organizadas preferencialmente na forma de universidades.

De acordo com a Confederação Nacional dos Trabalhadores em Educação (CNTE) (2008), a política de formação inicial e continuada, proposta somente através dos cursos a distância ofertados pela UAB, é uma fragilidade do PDE. Segundo Helena de Freitas (2007b), o PDE é totalmente omisso quanto à formação inicial de professores nas universidades públicas, uma vez que enfatiza a ampliação da UAB como alternativa para o atendimento massivo da formação. Para a autora (FREITAS, 2007b) é uma política compensatória e emergencial que visa a suprir a ausência de ofertas de cursos na rede pública de Educação Superior.

A Universidade Aberta do Brasil não é propriamente uma universidade, mas um sistema que busca articular as instituições públicas já existentes com o objetivo de expandir, por meio da modalidade a distância, os cursos de Educação Superior no pais. A UAB é um sistema integrado por universidades públicas, sob a regulação da CAPES, que oferece cursos de nivel superior para camadas da população que têm dificuldade de acesso à formação universitária, por meio do uso da metodologia da educação a distância. Os professores que atuam na educação básica têm prioridade de formação, seguidos dos dirigentes, gestores e trabalhadores em educação básica dos estados, municipios e do Distrito Federal (CAPES, 2010).

Assim como a UAB, o Pibid ${ }^{6}$ é um programa da Capes. Trata-se de um programa que selecionará, por meio de edital, instituições federais de ensino superior e centros federais de educação tecnológica que possuam cursos de licenciatura e que tenham firmado convênio ou acordo de cooperação com as redes de Educação Básica públicas dos municípios, dos Estados ou do Distrito Federal.

0 programa concederá bolsas de iniciação à docência a estudantes, bolsas de coordenação a professores coordenadores e bolsas de supervisão aos professores supervisores, a fim de incentivar a formação de professores para a Educação Básica, especialmente para o Ensino Médio, onde a demanda é maior. A ação atende ao Plano de Metas Compromisso Todos pela Educação, previsto no PDE, para elevar o Ideb.

60 primeiro edital foi lançado em 12 de dezembro de 2007. 
A UAB é uma política estratégica para resolver o problema da falta de professores na Educação Básica. Contudo, os polos de apoio presencial não possuem as mesmas condições de estudo e trabalho das instituições de Ensino Superior, prejudicando a inserção dos alunos num espaço acadêmico que possibilite a articulação entre ensino, pesquisa e extensão. A UAB tende a ser mais um espaço de profissionalização do que de efetiva formação integral dos sujeitos.

Apesar de a UAB ser um programa da Capes que tem como prioridade o atendimento da demanda emergencial por formação de professores, não fica claro se este programa é temporário ou se concretizará como uma política de formação superior permanente. Luiz Carlos de Freitas (2007, p. 974) considera que "estamos agora diante de um 'neotecnicismo' [...], em que acordos de gestão com prefeitos (em cascata para dentro dos sistemas), responsabilização e treinamento do professor via Capes e Universidade Aberta do Brasil são a estratégia." A incorporação da UAB e do Pibid como programas da Capes compõe o conjunto de ações que the são atribuidas a partir do novo papel que assume a partir de 2007.

Desde então, a Capes passou a subsidiar o MEC na formulação de políticas de formação de profissionais do magistério para a Educação Básica e Superior. Ao ampliar seu campo de atuação, assumiu responsabilidades que antes eram da competência da Secretaria de Educação Básica, da Secretaria de Educação Superior e da Secretaria de Educação a Distância. A Capes, como reguladora da formação dos profissionais da educação, é uma agência mediadora do Estado que centraliza decisões. Ao longo de seus anos de atuação, demonstrou ser eficiente nos processos reguladores da pesquisa e produção de conhecimento na pós-graduação. Mas, apesar do aspecto positivo de centralizar a pesquisa na pós-graduação e o seu caráter de cientificidade, Kuenzer e Moraes (2005) destacam como aspectos negativos a exacerbação quantitativista e o surto produtivista gerado pela ênfase nas exigências à produção acadêmica. 0 objetivo central da "nova" Capes é, de acordo com Helena de Freitas (2007a, p. 1218, grifo da autora),

[...] implantar um sistema de avaliação dos cursos existentes, nos moldes do que a instituição adota para a pós-graduação, transpondo, portanto, para os cursos de licenciaturas, os padrões de excelência da avaliação da pós-graduação.

Desse modo, a autora alerta para o fato de que a Educação Básica e seus profissionais ficam submetidos à lógica produtivista, instituindo a competitividade entre as IES e entre os professores da Educação Básica, como tem acontecido com a pós-graduação.

Nesse sentido, Helena de Freitas (2007a) destaca que é necessário um olhar atento no sentido de identificar em que medida as atuais iniciativas de regulação realmente desenvolverão processos de elevação da qualidade da Educação Básica. 
Tal atenção é importante para que, no âmbito das contradições, seja possível estabelecer uma contrarregulação que possibilite o desenvolvimento de uma formação de caráter emancipador.

0 que se evidencia é que há, nesse contexto, uma reposição do papel centralizador do Estado por meio de agências de regulação. No Brasil, a Capes é uma agência reguladora que, sob a ótica do Estado gerencialista, exerce, com eficiência, a avaliação dos resultados da pós-graduação, o que faz com que ela seja indispensável, deste ponto de vista, para a formação dos profissionais do magistério da Educação Básica.

0 uso do termo regulação, embora amplamente utilizado na área econômica, ganha maior vigor no Brasil a partir do processo de reforma do Estado implementado nas últimas duas décadas do século passado. Entretanto, os estudos sobre regulação são recentes na literatura educacional brasileira e sua discussão se encontra muito restrita aos meios acadêmicos. De acordo com Oliveira, a referência principal ao conceito de regulação é encontrada em Aglieta (1979 apud OLIVEIRA, 2005) que nos ensina que estudar um modo de produção é colocar a descoberto quais são as relações determinantes que se reproduzem nas e pelas transformações sociais e, ainda, verificar as formas sob as quais se realizam. Assim, explicitar a regulação de um modo de produção requer expressar como se reproduz a estrutura determinante de uma sociedade. Nesse contexto, o novo modelo de regulação das políticas educativas, que emergiu a partir dos anos de 1990, faz parte de um ciclo de reformas mais amplas, pois é um importante instrumento de regulação social.

Embora o conceito de regulação assuma uma pluralidade de significados, Barroso (2005) destaca que a regulação, enquanto modo de coordenação dos sistemas educativos, pode ser interpretada como a principal responsável por assegurar o equilibrio, a coerência, mas também a transformação desse mesmo sistema. Por isso, 0 processo de regulação compreende não só a produção de regras que orientam o funcionamento do sistema, mas também o (re)ajustamento da diversidade de ações dos sujeitos em função dessas mesmas regras. Para o autor, a regulação do sistema educativo não é um processo único, automático e previsivel, mas sim um processo que resulta mais da regulação das regulações, do que do controle direto da aplicação de uma regra sobre ação dos regulados. Sendo assim, no âmbito do sistema público de ensino, o Estado é uma fonte essencial de regulação, mas não é a única, nem por vezes a mais decisiva nos resultados finais obtidos.

Barroso (2005) destaca, ainda, que o Estado regulador é mais flexível na definição dos processos e mais rígido na avaliação da eficiência e eficácia dos resultados. No Brasil, o controle dos resultados na área educacional se dá por meio de agências de regulação que tem o papel de conceber, financiar e avaliar políticas. 
Na análise de Helena de Freitas (2007a, p.1217), "a CAPES, juntamente com o FNDE, no financiamento, e o Inep, na avaliação da educação básica, compõe o tripé das agências reguladoras no campo da educação." Na visão de Sguissardi (2006), a Capes é uma agência financiadora, reguladora e credenciadora estatal que define as políticas educacionais de acordo com a conjuntura politicoeconômica predominante em cada governo, ancoradas em específicas concepções de desenvolvimento, do papel da universidade e do conhecimento, da ciência e da tecnologia.

As políticas do MEC/Capes dão prioridade à formação de professores para atender 'as demandas emergenciais no que se refere à falta de professores, bem como para melhoria da qualidade do ensino. Entretanto, a abordagem reformista da formação de professores apela para as mudanças de curto prazo que não conduzem a mudanças significativas. Isso se evidencia pela multiplicação de ações/programas para a formação de professores como a Rede Nacional de Formação Continuada de Professores, o Pró-Licenciatura, o PróLetramento, o Proinfantil, o Programa de Incentivo à Formação Continuada de Professores do Ensino Médio, o Prolind, o Prodocência e a Licenciatura em Educação Profissional e Tecnológica?.

A prioridade dada à formação de professores como solução para os resultados negativos obtidos pelo Ideb em detrimento de um investimento financeiro adequado revela a concepção de que condições subjetivas são suficientes para a resolução dos problemas educacionais. Sem uma melhoria significativa nas condições objetivas de trabalho, os avanços poderão ser insignificantes. As ações do MEC para a formação de professores têm contribuído para solucionar obstáculos imediatos, que impedem a melhoria da qualidade da educação, mas não os limites essenciais que poderiam contribuir para um projeto de educação positivamente sustentável em longo prazo. Essa é uma contradição presente nas políticas do MEC para a formação de professores, pois a superação dos limites fundamentais requer maiores investimentos na educação para a garantia de condições para uma sólida formação. Como consequência, o viés neopragmático se constitui como a essência das políticas de formação de professores, inviabilizando a consecução de um projeto de educação que contribua com as estratégias mais amplas de transformação social, pois impede a problematização do sentido econômico, político e cultural que condiciona a profissão docente.

7 0 Pró-Licenciatura é um programa destinado a professores que trabalham nos anos finais do Ensino Fundamental e no Ensino Médio dos sistemas públicos de ensino e que não possuem a licenciatura exigida para o exercício da função; o Pró-Letramento é um programa de formação continuada de professores, voltado para a melhoria da qualidade de aprendizagem da leitura/escrita e matemática nos anos iniciais do Ensino Fundamental; o Proinfantil destina-se à formação de professores da Educação Infantil em exercício nas creches e em escolas das redes públicas, municipais e Estaduais, bem como da rede privada sem fins lucrativos; o Prolind é um programa de apoio à Formação Superior e Licenciaturas Indígenas e o Prodocência é um Programa de Consolidação das Licenciaturas das instituições federais e estaduais de Ensino Superior. 
A influência da agenda pós-moderna nas políticas de formação de professores, materializada, sobretudo, pelo neopragmatismo, demonstra que as mudanças desejáveis são aquelas que "resolvem" os problemas conforme eles surgem, incidindo sobre os efeitos e não sobre as causas que os originam. Agir sobre as causas requer a mudança dos antagonismos estruturais subjacentes, e esse não parece ser o propósito do governo atual.

Em sentido diferente, a formação baseada na concepção socio-histórica permite a compreensão dos significados ideológicos presentes no contexto educacional porque explora os problemas educacionais em sua origem social e histórica. Para a Associação Nacional pela Formação dos Profissionais da Educação (ANFOPE), tal concepção de formação valoriza uma base comum nacional, a sólida formação teórica e interdisciplinar, a unidade entre teoria e prática, a gestão democrática, o compromisso social e ético, a avaliação permanente, a articulação entre formação inicial e continuada e o trabalho coletivo. Este último é indispensável para a transformação da prática de ensino e da prática social mais ampla. Tal concepção de formação foi construida pelo movimento de educadores, representado pela Anfope (ASSOCIAÇÃO NACIONAL..., 2002), e possui caráter amplo, que defende pleno domínio e compreensão da realidade, com consciência que possibilite interferir e transformar as condições da escola, da educação e da sociedade. Essa concepção de formação busca se desenvolver em bases teoricamente sólidas e é fundada nos princípios de uma formação de qualidade, com relevância social, distanciando-se largamente da concepção neopragmática predominante nas atuais políticas de formação de professores.

\section{Considerações finais}

A análise do PDE demonstra que ele é uma "colcha de retalhos", pois agrega inúmeras ações que já estavam em andamento sem estabelecer uma efetiva articulação. Sua aprovação ocorreu com participação restrita da sociedade civil e sem uma discussão sobre a sua relação com um novo PNE. Os fundamentos que o subsidiam não se distanciam de uma abordagem gerencialista, demonstrando uma aproximação com a concepção liberal de educação.

Os seis pilares conceituais do PDE - visão sistêmica da educação, territorialidade, desenvolvimento, regime de colaboração, responsabilização e mobilização social - demonstram, embora com pouca fundamentação, a concepção de educação assumida pelo governo. Tal concepção reforça os objetivos do Plano de Metas Compromisso Todos pela Educação, introduzindo a lógica da produtividade existente no setor privado.

A proposta de formação de professores presente no PDE enfatiza a importância do papel dos professores na melhoria da qualidade da educação. 0 destaque dado à formação do professor como estratégia para a solução dos problemas educacionais enfatiza a dimensão subjetiva do real e pode não contribuir para a melhoria das condições objetivas necessárias à qualidade da educação. 
A concepção neopragmatista fundamenta as políticas de formação de professores decorrentes do $\mathrm{PDE}$, pois enfatiza a busca de instrumentos úteis para as demandas imediatas da prática profissional, não contribuindo para o desenvolvimento de uma sólida e ampla formação.

Em sentido diferente, a concepção socio-histórica, historicamente defendida pela Anfope, pretende romper com o neopragmatismo, por isso concebe a formação de professores como um continuum entre formação inicial e continuada com caráter emancipatório, que permita a auto-organização dos professores para a construção de um projeto coletivo de educação, o qual venha a contribuir para a resistência ativa ao modelo de sociedade capitalista. Tal processo de formação é entendido como unitário e orgânico, pressupondo uma formação para o humano como forma de manifestação da educação integral dos homens.

\section{Referências}

ABRUCIO, F. L. Impacto do modelo gerencial na administração pública: um breve estudo sobre a experiência internacional recente. Brasília, DF: Enap, 1997.

AGUIAR, M. A. Atuação política: o querer, o poder e o fazer. Retratos da Escola, Brasilia, DF, n. 1, 2007.

BARROSO, J. 0 Estado, a educação e a regulação das políticas públicas. Educação e Sociedade, Campinas, SP, v. 26, n. 92, p. 725-751, out. 2005.

BRASIL. Decreto n ${ }^{0} 5.800$, de 8 de junho de 2006. Dispõe sobre o Sistema Universidade Aberta do Brasil - UAB. Diário Oficial da União, Brasília, DF, 9 jun. 2006. Seção 1, p. 4.

. O Plano de Desenvolvimento da Educação: razões, princípios e programas. Brasilia: Ministério de Educação, [2007].

CAPES. Conselho Técnico-Científico da Educação Básica. Diretoria de Educação Básica. Elementos para construção do Sistema Nacional de Formação de Professores. Brasília, DF: CAPES/DEB-P, 2008.

CARA, D. Plano de Desenvolvimento da Educação: ausências e limitações. Retratos da Escola, Brasilia, DF, n. 1, 2007.

CNTE. Posição da CNTE sobre o Plano de Desenvolvimento da Educação (PDE). Brasilia, DF, 2008. Disponivel em: <http://www.cnte.org.br>. Acesso em: 30 set. 2008. 
DOURADO, L. F. Políticas e gestão da educação básica no Brasil: limites e perspectivas. Educação e Sociedade, Campinas, SP, v. 28, n. 100, p. 921-946, 2007.

ENCONTRO NACIONAL DA ANFOPE, 11., 2002, Florianópolis. Documento final..., Florianópolis: Anfope, 2002. Não publicado.

FREITAS, H. C. L. de. A (nova) política de formação de professores: a prioridade postergada. Educação e Sociedade, Campinas, v. 28, n. 100, p. 1203-1230, 2007b. 2007a

PDE: responsabilidades e desafios. Retratos da Escola, Brasília, n. 1, 2007a. 2007b

FREITAS, L. C. de. Eliminação adiada: o ocaso das classes populares no interior da escola e a ocultação da (má) qualidade do ensino. Educação e Sociedade, Campinas, SP, v. 28, n. 100, p. 965-987, 2007.

GRACINDO, R. V. Notas sobre a educação básica no PDE. Retratos da Escola, Brasilia, DF, n. 1, 2007.

KATZ, D.; KHAN, R. L. Psicologia social das organizações. São Paulo: Atlas, 1970.

KUENZER, A. Z.; MORAES, M. C. M. de. Temas e tramas na pós-graduação em educação. Educação e Sociedade, Campinas, SP, v. 26, n. 93, p. 1341-1362, 2005.

MARTINS, A. S. A. Educação Básica no século XXI: o projeto do organismo "Todos pela Educação". Práxis Educativa, Ponta Grossa, v. 4, n. 1, p. 21-28, 2009.

MENDONÇA, E. F. A educação é um direito de cidadania. Retratos da Escola, Brasilia, DF, n. 1, 2007.

MÉSZÁROS, I. O desafio e o fardo do tempo histórico: o socialismo no século XXI. São Paulo: Boitempo, 2007.

OLIVEIRA, D. A. Regulação das políticas educacionais na América Latina e suas consequências para os trabalhadores docentes. Educação e Sociedade, Campinas, SP, v. 26, n. 92, p. 753-775, out. 2005.

RUIZ, A. I. Ausências do PDE. Retratos da escola. Brasília, DF, n. 1, 2007.

SAVIANI, D. Desafios da construção de um sistema nacional articulado de educação. Trabalho, educação e saúde, Rio de Janeiro, v. 6, n. 2, p. 213-231, 2008. 
SAVIANI, D. PDE: Plano de Desenvolvimento da Educação: análise crítica da política do MEC. Campinas, SP: Autores Associados, 2009.

. 0 Plano de Desenvolvimento da Educação: análise do projeto do MEC.

Educação e Sociedade, Campinas, SP, v. 28, n. 100, p. 1231-1255, 2007.

SGUISSARDI, V. A avaliação defensiva no "modelo CAPES de avaliação": é possivel conciliar avaliação educativa com processos de regulação e controle do Estado?. Perspectiva, Florianópolis, v. 24, n. 1, p. 49-88, jan./jun. 2006.

VASCONCELLOS, M. J. E. de. Pensamento sistêmico: o novo paradigma da ciência. 8. ed. Campinas, SP: Papirus, 2009.

VON BERTALANFFY, L. Teoria geral dos sistemas. 2. ed. Petrópolis: Vozes, 1975.

Recebido em: 08/12/2010

Aceito para publicação em: 31/08/2011 